40 (2) | 2011

Varia

1945-2011

\title{
Carlos Iván Degregori
}

1945-2011

Carmen Salazar-Soler

\section{(2) OpenEdition}

Journals

Edición electrónica

URL: http://journals.openedition.org/bifea/1561

DOI: 10.4000/bifea.1561

ISSN: 2076-5827

Editor

Institut Français d'Études Andines

Edición impresa

Fecha de publicación: 1 agosto 2011

Paginación: 453-457

ISSN: 0303-7495

Referencia electrónica

Carmen Salazar-Soler, « Carlos Iván Degregori », Bulletin de l'Institut français d'études andines [En línea], 40 (2) | 2011, Publicado el 01 febrero 2012, consultado el 07 noviembre 2020. URL : http:// journals.openedition.org/bifea/1561; DOI : https://doi.org/10.4000/bifea.1561

\section{(c) (i) (9)}

Les contenus du Bulletin de l'Institut français d'études andines sont mis à disposition selon les termes de la licence Creative Commons Attribution - Pas d'Utilisation Commerciale - Pas de Modification 4.0 International. 


\section{In memoriam}

\section{CARLOS IVÁN DEGREGORI}

1945-2011

El Instituto Francés de Estudios Andinos (IFEA) ha tenido a bien confiarme la redacción de algunas palabras sobre el querido, respetado y admirado colega y amigo Carlos Iván Degregori. Carlos Iván ha recibido y recibe aún en estos días muchos homenajes que muestran no solo el reconocimiento, admiración y respeto hacia el antropólogo e intelectual que fue, sino que también testimonian el gran afecto de las personas que lo conocieron. Muchos de estos homenajes han realzado su trayectoria académica y la importancia de su obra para el país, por ello quisiera en estas páginas recordar sus vínculos con Francia, con el IFEA, con la academia francesa y con los colegas y amigos que residimos y trabajamos en Francia.

Conocí a Carlos Iván a mediados de los años 1980, cuando antes de partir a Francia trabajé en el Instituto de Estudios Peruanos (IEP) en un proyecto dirigido por Marisol de la Cadena. Luego dejé de frecuentarlo debido a mi trabajo en Francia, aunque lo visité algunas veces cuando estuve de paso por Lima. Pero fue en 2005, donde realmente retomé contacto con él y fue con ocasión del IV Congreso Nacional de Antropología, luego que pronunciara el impactante e importante discurso de inauguración de dicho evento: «¿Cómo despertar a la bella durmiente? Por una antropología para comprender un país escindido». Este alegato por un despertar de la antropología peruana tuvo un impacto que trasciende las fronteras del país para alcanzar también la antropología que se hace sobre el Perú en el extranjero y, en lo que nos concierne, en Francia. Para los antropólogos y sociólogos franceses o aquellos que ejercemos en Francia y escuchamos ese discurso o que lo leímos, sus palabras fueron no solo una lección, sino también un aliciente para aquellos que luchamos por que la antropología sobre el Perú que se hace en dicho país «cuestione y rompa mitos, promueva debates» y responda a la realidad dando cuenta de los cambios de la sociedad peruana, dejando de lado viejos esquemas que no ayudan a explicarla ni a entenderla. El mensaje recibido fue que en Francia también necesitamos idespertar a la bella durmiente! 
Personalmente, este discurso así como su compendio No hay país más diverso. Compendio de antropología peruana, me ayudaron a escribir una suerte de balance de los estudios que desde la academia francesa se han hecho sobre el Perú, artículo que luego formaría parte de un breve libro recopilado por Carlos Iván y Pablo Sandoval (2008).

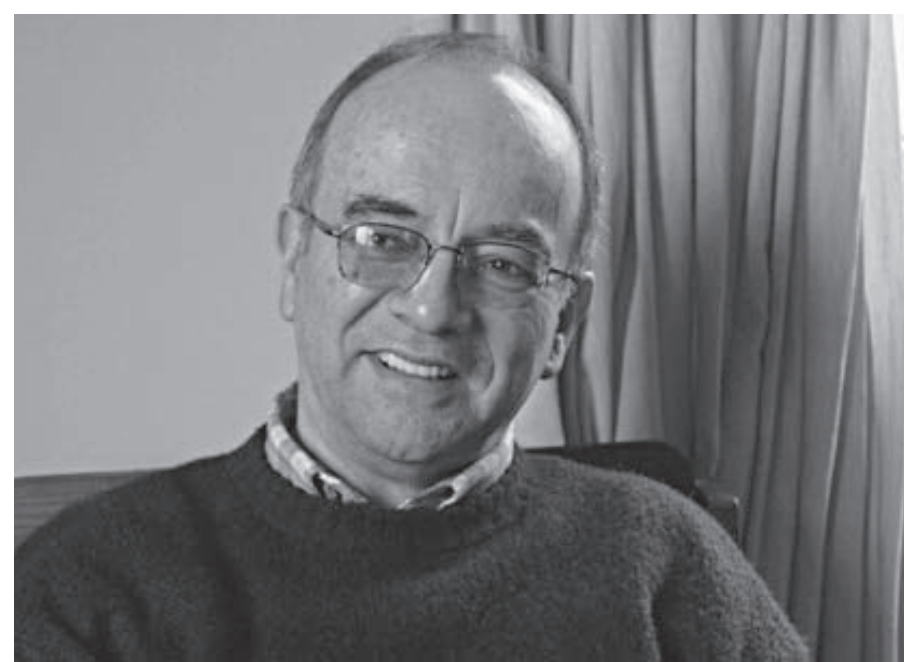

En 2008, Carlos Iván Degregori se hizo acreedor de la cátedra Simón Bolívar, otorgada por el Instituto de Altos Estudios de América Latina (IHEAL) de la Universidad Paris III-Sorbona, gracias a la iniciativa y apoyo de Christian Gros. Esta cátedra, nos proporcionó el privilegio y el placer de tenerlo durante tres meses como profesor en dicho centro de estudios. No se trataba de la primera vez que Francia tenía el honor de recibirlo como profesor: a fines de los años 1990 fue invitado a la Escuela de Altos Estudios en Ciencias Sociales de París (EHESS) por el sociólogo Michel Wieviorka para presentar sus trabajos sobre violencia y Sendero Luminoso. Las clases que impartió en el IHEAL versaron sobre la problemática de la etnicidad y sobre el trabajo de las Comisiones de la Verdad y Reconciliación en Perú y Guatemala. Además de estos cursos, Carlos Iván dio algunas conferencias sobre diferentes problemáticas tales como desigualdad, multiculturalismo, interculturalidad, etc. Estas charlas respondieron a la inquietud e interés de colegas y estudiantes, y suscitaron múltiples debates. Su obra, conferencias y conversaciones sobre Sendero Luminoso o sobre la Comisión de la Verdad y la Reconciliación han inspirado y contribuido valiosamente a las investigaciones sobre violencia y memoria de colegas y estudiantes franceses o que ejercen en Francia.

Las enseñanzas de Carlos Iván no se limitaron a los claustros académicos, sino que los que tuvimos el privilegio de estar cerca de él durante esos meses nos beneficiamos de sus observaciones a lo largo de conversaciones, acuciosas reflexiones y agudos comentarios. Así como de su sentido del humor y de su magnífica e iluminadora sonrisa, a pesar de que empezaban a aflorar los primeros síntomas de la enfermedad. Todas sus observaciones sobre la realidad francesa le hacían reflexionar sobre la realidad peruana.

De esta manera, aparecieron una diversidad de temas y problemas sobre el Perú que eran pensados a través de lo que él observaba en Francia y de una comparación de las dos realidades. Quisiera aquí recordar dos de ellos. En su 
recorrido por algunos barrios parisinos cosmopolitas, en donde la presencia de emigrantes o de hijos de emigrantes provenientes en particular del Magreb o de diferentes países de África era notoria, conversando sobre las revueltas protagonizadas por los jóvenes de algunos suburbios de la capital francesa en 2007, Carlos Iván se interrogaba sobre las políticas de inclusión de las poblaciones consideradas como los «otros», sobre el multiculturalismo, la interculturalidad, el racismo, la discriminación y la exclusión en Francia. Luego regresaba a la realidad peruana y trazaba comparaciones, establecía similitudes o detectaba diferencias con el fin de analizarla para transformarla. Constataba así, que tanto aquí como allá se discrimina «a aquellos pobres que además son culturalmente diversos». Constataba también los problemas de inclusión social en Europa. Volvía además sobre el rol de la Antropología, en particular la peruana, recordando la pregunta formulada ya en uno de sus libros, a decir «¿Qué pasa cuando el Otro no está en una isla lejana, una selva impenetrable o algún desierto calcinante, sino dentro del propio país, literalmente a la vuelta de la esquina o incluso dentro del propio antropólogo?» (Degregori, 2000: 23).

Otro gran tema abordado a lo largo de su estadía y que guarda relación con el anterior, fue el de la educación, su reflexión sobre el contenido democratizador del modelo francés de la «escuela republicana». Como lo ha mencionado ya P. Ames en su artículo de homenaje a Carlos Iván (2011), éste se preguntaba por la relación entre educación y desarrollo de la ciudadanía. Se interrogaba sobre si el modelo de educación francés seguía cumpliendo los objetivos del pasado, si el Estado seguía apostando por la educación pública o si, como en el Perú, le había dado la espalda. Reflexionaba sobre este modelo pensando en cómo hacer para que la educación pública en el Perú sea de calidad. Se preocupaba también por conocer cuánto del sistema de educación francés había afectado/eliminado las lenguas regionales como el bretón o el vasco, lo hacía pensando en la necesidad de una educación bilingüe e intercultural en el Perú.

Recuerdo que una tarde de 2008, luego de una caminata por la capital francesa Carlos Iván se detuvo de pronto y con una enorme sonrisa declaró que pensaba que él podría vivir en París porque le parecía una ciudad humana, donde todavía existían barrios, unos muy diferentes de otros y donde además había vida de barrio.

En septiembre de 2008, en el marco de las actividades de homenaje por los 60 años del IFEA, tuve el honor y placer de organizar conjuntamente con Carlos Iván la mesa redonda «Antropología del Estado en los países andinos», destinada a dar cuenta de una de las nuevas perspectivas de investigación en el área de la antropología de la región andina.

La última vez que conversé con Carlos Iván fue en enero de este año cuando lo visité en su casa de Barranco con un antiguo colaborador suyo y amigo, el antropólogo Mirko Solari Pita, quien actualmente realiza estudios de doctorado en Francia. Pasamos la tarde, iluminada por la calidez de nuestro amigo, conversando de múltiples temas; Carlos Iván preguntó por amigos y colegas en Francia, mostró su preocupación por los últimas noticias llegadas de este país que mostraban a la política de extrema derecha Marine Le Pen, del Front Nacional, encabezando 
los sondeos de las elecciones presidenciales del 2012. Compartió con nosotros la alegría de la publicación de su último libro (Degregori, 2011), cuyo primer ejemplar había recibido durante las fiestas navideñas, y nos contó la historia de la carátula. Mostró interés por conocer los avances de las investigaciones doctorales de Mirko y me obsequió un $\mathrm{CD}$ del documental realizado por su hermano Felipe sobre Chungui con la promesa de difundirlo en Francia entre los estudiantes, colegas y el público en general. Al momento de escribir estas líneas recuerdo a Carlos Iván despidiéndonos al final de la tarde con la esperanza de poder, en nuestra próxima conversación, brindar con unas copas de vino. No podremos brindar contigo Carlos Iván, sin embargo Mirko y yo cumpliremos nuestro compromiso de difundir en Francia, con la autorización de tu hermano claro está, el documental sobre Chungui.

En cuanto a sus relaciones más formales con el IFEA, cabe recordar que Carlos Iván Degregori formó parte del conjunto de especialistas que integraban el «comité de suivi» de dicho instituto que se reúne cada 2 años.

Este 13 de julio último, Carlos Iván Degregori recibió de la Embajada de Francia en el Perú un reconocimiento póstumo por su lucha por la exclusión y defensa de los derechos humanos. La embajadora de Francia en el Perú, Cécile Mouton-Brady de Pozzo di Borgo reconoció en la persona de Carlos Iván Degregori una de las figuras más importantes en el Perú y en toda la región en la defensa permanente de los derechos humanos, señalando en su discurso que «su palabra y su obra no solo muestran una luz intelectual, sino también un compromiso íntegro y sin vacilación con las víctimas de la exclusión, de la violencia y de la discriminación», al momento de dedicar a su memoria las placas de la Declaración Universal de los Derechos Humanos que se instalaron en la Plaza Francia.

Los colegas, estudiantes y amigos que residimos en Francia no pudimos despedirnos y expresarle lo que estas páginas intentan decir: iGracias Carlos Iván por tu luz, tus enseñanzas, tu lucha contra la desigualdad y defensa de los derechos humanos, tu calidez, honradez, dulzura y tu inmensa sonrisa!

\section{Referencias citadas}

AMES, P., 2011 - Educación cultura y política: una mirada a la obra de Carlos Iván Degregori. Revista Argumentos, año 5, n. ${ }^{\circ}$ 3, julio.

DEGREGORI, F., 2010 - Chungui horror sin lágrimas... una historia peruana. Un documental dirigido por Felipe Degregori; Lima: Buenaletra, IEP.

DEGREGORI, C. I., 2000 - No hay país más diverso. Compendio de antropología peruana, 444 pp.; Lima: IEP, PUCP, UP.

DEGREGORI, C. I., 2005 - ¿Cómo despertar a la bella durmiente? Por una antropología para comprender un país escindido. Discurso pronunciado en ocasión de la inauguración del IV Congreso de Investigaciones en Antropología; Lima: Universidad Mayor de San Marcos, PUCP. 
In memoriam Carlos Iván Degregori

DEGREGORI, C. I., 2011 - Qué difícil es ser Dios. El Partido Comunista del Perú-Sendero Luminoso y el conflicto armado interno en el Perú: 1980-1999, 325 pp.; Lima: IEP.

DEGREGORI, C. I. \& SANDOVAL, P. (eds.), 2008 - Saberes periféricos. Ensayos sobre antropología en América Latina, 250 pp.; Lima: IEP, IFEA.

\section{Carmen SALAZAR-SOLER}

